OPEN ACCESS

Edited by:

Ivan Berg,

Universität Münster, Germany

Reviewed by:

Kathleen Scott,

University of South Florida,

United States

Marina G. Kalyuzhanaya

San Diego State University,

United States

*Correspondence: Mirjam Perner

mirjam.perner@uni-hamburg.de

Specialty section:

This article was submitted to Microbial Physiology and Metabolism,

a section of the journal

Frontiers in Microbiology

Received: 12 April 2017 Accepted: 28 June 2017

Published: 12 July 2017

Citation:

Böhnke S and Perner M (2017)

Unraveling RubisCO Form I and Form II Regulation in an Uncultured

Organism from a Deep-Sea Hydrothermal Vent via Metagenomic and Mutagenesis Studies. Front. Microbiol. 8:1303. doi: 10.3389/fmicb.2017.01303

\section{Unraveling RubisCO Form I and Form II Regulation in an Uncultured Organism from a Deep-Sea Hydrothermal Vent via Metagenomic and Mutagenesis Studies}

\author{
Stefanie Böhnke and Mirjam Perner* \\ Molecular Biology of Microbial Consortia, Biocenter Klein Flottbek, University of Hamburg, Hamburg, Germany
}

Ribulose-1,5-bisphosphate carboxylase/oxygenase (RubisCO) catalyzes the first major step of carbon fixation in the Calvin-Benson-Bassham (CBB) cycle. This autotrophic $\mathrm{CO}_{2}$ fixation cycle accounts for almost all the assimilated carbon on Earth. Due to the primary role that RubisCO plays in autotrophic carbon fixation, it is important to understand how its gene expression is regulated and the enzyme is activated. Since the majority of all microorganisms are currently not culturable, we used a metagenomic approach to identify genes and enzymes associated with RubisCO expression. The investigated metagenomic DNA fragment originates from the deep-sea hydrothermal vent field Nibelungen at $8^{\circ} 18^{\prime} \mathrm{S}$ along the Mid-Atlantic Ridge. It is 13,046 bp and resembles genes from Thiomicrospira crunogena. The fragment encodes nine open reading frames (ORFs) which include two types of RubisCO, form I (CbbL/S) and form II (CbbM), two LysR transcriptional regulators (LysR1 and LysR2), two von Willebrand factor type A (CbbO-m and CbbO-1), and two AAA+ ATPases (CbbQ-m and CbbQ-1), expected to function as RubisCO activating enzymes. In silico analyses uncovered several putative LysR binding sites and promoter structures. Functions of some of these DNA motifs were experimentally confirmed. For example, according to mobility shift assays LysR1's binding ability to the intergenic region of lysR1 and $c b b L$ appears to be intensified when CbbL or LysR2 are present. Binding of LysR2 upstream of cbbM appears to be intensified if CbbM is present. Our study suggests that CbbQ-m and CbbO-m activate CbbL and that LysR1 and LysR2 proteins promote CbbQ-m/CbbO-m expression. CbbO-1 seems to activate $\mathrm{CbbM}$ and $\mathrm{CbbM}$ itself appears to contribute to intensifying LysR's binding ability and thus its own transcriptional regulation. CbbM furthermore appears to impair $c b b L$ expression. A model summarizes the findings and predicts putative interactions of the different proteins influencing RubisCO gene regulation and expression.

Keywords: autotrophic $\mathrm{CO}_{2}$ fixation, Calvin-Benson-Bassham (CBB) cycle, RubisCO gene regulation, LysR, $\mathrm{CbbQ}, \mathrm{CbbO}$, heterologous gene expression, non-native system 


\section{INTRODUCTION}

Ribulose-1,5-bisphosphate carboxylase/oxygenase (RubisCO, EC 4.1.1.39) is believed to be the most abundant enzyme on Earth (Ellis, 1979; Raven, 2009). It is the key enzyme of the autotrophic Calvin-Benson-Bassham (CBB) cycle and catalyzes the carboxylation of ribulose-1,5-bisphosphate (RuBP) to 3-phosphoglycerate (3-PGA) (Berg, 2011). Since the CBB cycle is estimated to account for most of Earth's net primary production (>99.5\% of $105 \times 10^{9}$ tons/year) (Field et al., 1998; Raven, 2013), it is important to understand RubisCO expression and its activation in many different organisms.

The RubisCO enzyme is widespread and can be found in plants, algae, cyanobacteria, many autotrophic bacteria (phototrophs and chemolithotrophs), and archaea (Tabita et al., 2007; Hauser et al., 2015). Although four types of structural RubisCOs are known, only the RubisCO form I (CbbLS) and the form II (CbbM) are evidenced to operate in the classical CBB cycle (Berg, 2011). For the expression and activation of a catalytically active form I and form II RubisCO distinct transcriptional regulators and activases are essential (Maddocks and Oyston, 2008; Dangel and Tabita, 2015; Tsai et al., 2015). LysR-type transcriptional regulators (LTTRs) have been found adjacent to the structural RubisCO genes in several genomes and are evidenced to regulate their transcription (Dangel and Tabita, 2015). LTTRs can function as an activator and/or as a repressor for their target genes (Maddocks and Oyston, 2008 and references therein), but can also positively autoregulate their own transcription (Axler-DiPerte et al., 2006). Indeed, LTTR associated regulation can be highly complex as is indicated by LTTRs which need to interact with other transcriptional regulators (Joshi et al., 2013; Dangel et al., 2014). Since RubisCO forms inhibited complexes with its substrate RuBP but also with other sugar phosphates (Tsai et al., 2015), the removal of the active site inhibitor is essential for proceeding with the RubisCO catalyzed carboxylation reaction. In case of plant green-type and $\alpha$-proteobacterial red-type form I RubisCOs, this is done by the RubisCO activase ( $\mathrm{rca}$ ) and CbbX, respectively (Parry et al., 2008; Mueller-Cajar et al., 2011). CbbQ (AAA+ATPase) and $\mathrm{CbbO}$ (von Willebrand factor type A) represent a third class of RubisCO activases and were shown to act on greentype form I RubisCOs of chemoautotrophic bacteria (Tsai et al., 2015).

Given that the majority of microorganisms are currently unculturable (Amann et al., 1995), we recently developed an activity-based screen, which enables us to seek RubisCO active clones from metagenomic fosmid libraries (Böhnke and Perner, 2015). One of these newly discovered RubisCO active metagenomic clones stems from a fosmid library constructed with DNA from the Nibelungen vent field ( $8^{\circ} 18^{\prime} \mathrm{S}$ on the Mid-Atlantic Ridge): It exhibited similarities to genes from the gammaproteobacterial Thiomicrospira crunogena XCL-2 (96\%). Our metagenomic fragment encodes a $13 \mathrm{~kb}$ RubisCO gene cluster and flanking DNA regions of additional $22.2 \mathrm{~kb}$. The $13 \mathrm{~kb}$ DNA fragment encodes two divergently directed reading frames: (i) lysR1, lysR2, $c b b M, c b b Q-m$, and $c b b O-m$, and (ii) $c b b L, c b b S, c b b Q-1$, and $c b b O-1$. To date, only one study has ever investigated regulatory mechanisms in metagenome derived RubisCO gene clusters (Böhnke and Perner, 2015). Here, total RubisCO activity was significantly influenced when $c b b L$ and $c b b M$ neighboring genes were knocked out (Böhnke and Perner, 2015), but it remained unclear which of the two RubisCOs was primarily affected by these mutations. While most of the studies on RubisCO regulation investigate the regulation of alphaproteobacterial RubisCOs (Paoli et al., 1998; Dubbs and Tabita, 2003; van Keulen et al., 2003; Dubbs et al., 2004; Joshi et al., 2013; Dangel et al., 2014), little work exists on the regulatory machinery behind gammaproteobacterial RubisCO transcription (Kusano and Sugawara, 1993). The arrangement of alphaproteobacterial RubisCOs and their associated genes as well as the location of the RubisCO gene clusters on the genome are very different to what is observed on our metagenomic fragment. For example, while the alphaproteobacterial Rhodobacter capsulatus RubisCO form I gene cluster is arranged like our RubisCO form I gene cluster (lysR1 cbbLSQO), the RubisCO form II gene cluster is considerably different to that on our metagenomic fragment (cbbFPTGAM versus cbbMQO, respectively) (Paoli et al., 1998) suggesting different interactions with respect to regulatory processes. Also, our metagenomic RubisCO form I and form II gene clusters are located within each other's vicinity on a $13 \mathrm{~kb}$ DNA fragment. In contrast, the RubisCO gene clusters of the so far investigated Alphaproteobacteria are either encoded on different chromosomes (Rhodobacter sphaeroides) or on distant regions of the genome (separated by $2 \mathrm{Mb}$ or $1.4 \mathrm{Mb}$, Rhodobacter capsulatus and Rhodopseudomonas palustris, respectively) (Paoli et al., 1998; Dubbs and Tabita, 2004; Joshi et al., 2013). The here investigated metagenome derived form I and form II RubisCOs, thus, represent a unique opportunity to investigate the role that genes and respective products have on the expression and activation of two forms of RubisCOs from an uncultured Gammaproteobacterium colonizing a chemically dynamic environment.

\section{MATERIALS AND METHODS}

\section{Bacterial Strains, Vectors, and Constructs, Media, and Growth Conditions}

The bacterial strains, vectors, and constructs used in this study are summarized in Table 1. Escherichia coli cultures were routinely grown on lysogeny broth (LB) medium (Bertani, 1951). For cloning procedures cultures were incubated at $37^{\circ} \mathrm{C}$. If cultivated for measuring recombinant RubisCO activities, the growth temperature was lowered to $28^{\circ} \mathrm{C}$, while cultures grown as part of over expression experiments were incubated at $17^{\circ} \mathrm{C}$ or $22^{\circ} \mathrm{C}$. If required, the following supplements were added: ampicillin, $100 \mu \mathrm{g} \mathrm{ml}{ }^{-1}$; 5bromo-4-chloro-3-indolyl- $\beta$-D-galactopyranoside (X-gal), $50 \mu \mathrm{g} \mathrm{ml}{ }^{-1}$, chloramphenicol, $12.5 \mu \mathrm{g} \mathrm{ml}{ }^{-1}$; isopropyl $\beta$-D-1-thiogalactopyranoside (IPTG), $100 \mu \mathrm{g} \mathrm{ml}^{-1}$ (cloning) 
TABLE 1 | Strains, vectors, and constructs used in this study.

\begin{tabular}{|c|c|c|c|}
\hline Strain, plasmid or construct & Genotype or characteristics & Size [bp] & Source \\
\hline Epi300 ${ }^{\mathrm{TM}}{ }_{-} \mathrm{T} 1^{\mathrm{R}}$ & $\begin{array}{l}\mathrm{F}^{-}, \text {mcrA, } \Delta \text { (mrr-hsdRMS-mcrBC) } \Phi 80 d l a c Z \Delta M 15, \\
\Delta / a c X 74, \text { recA1 endA1, araD139, } \Delta(\text { ara, leu }) 7697, \\
\text { gal } \mathrm{U}, \text { galK, } \lambda^{-}, \text {rpsL, nupG, trfA, tonA, dhfr }\end{array}$ & / & epicentre $^{\circledast}$ (Madison, WI, United States) \\
\hline E. coli Rosetta-gami 2 & 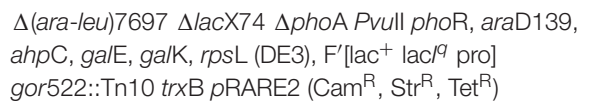 & / & Novagen/Merck (Darmstadt, Germany) \\
\hline pCC1FOS ${ }^{T M}$ & $\begin{array}{l}\text { Fosmid cloning vector, oriV, ori2, redF, repE, parA, } \\
\text { parB, parC, cos, loxP, lacZ, Cam }{ }^{\mathrm{R}} \text {, P T7 }\end{array}$ & 8,139 & epicentre $^{\circledR}$ (Madison, WI, United States) \\
\hline pet21a & $\begin{array}{l}\text { Expression vector, lacl, } \mathrm{Amp}^{\mathrm{R}}, \mathrm{P} \mathrm{T} 7, \mathrm{C} \text {-terminal His } \\
\text { 6-tag coding sequence }\end{array}$ & 5,443 & Novagen/Merck (Darmstadt, Germany) \\
\hline $71 \mathrm{C} 2$ & $\begin{array}{l}\text { pCC1FOS metagenomic fosmid vector containing a } \\
\text { RubisCO gene cluster (cbbO-mQ-mM lysR2 lysR1 } \\
\text { cbbLSQ-1O-1) and } 22.2 \mathrm{~kb} \text { flanking DNA }\end{array}$ & 35,195 & Böhnke and Perner, 2015 \\
\hline $71 \mathrm{C} 2 \|$ & $\begin{array}{l}\text { pCC1FOS vector containing a metagenome derived } \\
\text { RubisCO gene cluster (cbbO-mQ-mM lysR2 lysR1 } \\
\text { cbbLSQ-1O-1) subcloned from } 71 \mathrm{C} 2\end{array}$ & 13,023 & Böhnke and Perner, 2015 \\
\hline $22 \| \Delta c b b M$ & $\begin{array}{l}\text { Transposon clone based on } 71 \mathrm{C} 2 \mathrm{Il} \text { with an insertion in } \\
\text { the cbbM structural gene at position } 171 \text { aa of } 459 \mathrm{aa}\end{array}$ & 14,244 & Böhnke and Perner, 2015 \\
\hline $24 \| \Delta c b b L$ & $\begin{array}{l}\text { Transposon clone based on } 71 \mathrm{C} 2 \mathrm{Il} \text { with an insertion in } \\
\text { the } c b b L \text { structural gene at position } 41 \text { aa of } 472 \mathrm{aa}\end{array}$ & 14,244 & Böhnke and Perner, 2015 \\
\hline pet21a::cbbL & $c b b L$ cloned from $71 \mathrm{C2}$ & 1,421 & This study \\
\hline pet21a::cbbM & cbbL cloned from $71 \mathrm{C2}$ & 1,386 & This study \\
\hline pet21a::lysR1 & lysR1 cloned from 71C2 & 932 & This study \\
\hline pet21a::lysR2 & lysR2 cloned from 71C2 & 950 & This study \\
\hline
\end{tabular}

Characteristics of double transposon clones constructed in this study are indicated in Supplementary Table 1.

or $0.1-1 \mathrm{mM}$ (expression); kanamycin, $50 \mu \mathrm{g} \mathrm{ml} \mathrm{m}^{-1}$, and tetracycline, $10 \mu \mathrm{g} \mathrm{ml}^{-1}$.

\section{Construction of Double Transposon Mutant Libraries}

Two double transposon mutant libraries were constructed from two versions of the $13 \mathrm{~kb}$ metagenomic fragment consisting of the RubisCO gene cluster ( $c b b O-m Q-m M$ lysR2 lysR1 cbbLSQ-1O-1; accession: KJ639815.1) using the EZ-Tn5 ${ }^{\mathrm{TM}}$ $<$ TET-1> Tnp Transposome ${ }^{\mathrm{TM}}$ Kit (epicentre ${ }^{\circledR}$, Madison, WI, United States) according to manufacturer's instructions, with chemically competent Epi300 ${ }^{\mathrm{TM}}-\mathrm{T} 1^{\mathrm{R}}$ (epicentre $^{\circledR}$ ) as the host. One library was constructed with transposon clone 22II, where the $c b b M$ structural gene was deleted $(\Delta c b b M)$. The second library was constructed using transposon clone 24II, where the $c b b L$ structural gene was impaired $(\Delta c b b L)$. Clones containing fosmids with $<$ TET-1> insertions were selected on LB agar plates using the following antibiotic additions: (i) chloramphenicol $\left(12.5 \mu \mathrm{g} \mathrm{ml}^{-1}\right)$ for selecting the fosmid vector, (ii) kanamycin $\left(50 \mu \mathrm{g} \mathrm{ml}^{-1}\right)$ to verify the presence of the first insertion, i.e., $\Delta c b b M$ or $\Delta c b b L$, and (iii) tetracycline $\left(100 \mu \mathrm{g} \mathrm{ml}^{-1}\right)$ to verify the insertion of the second transposon element. Fosmids of double transposon clones were isolated from autoinduced cultures (for detailed information on autoinduction procedure see the manual for the CopyControl ${ }^{\mathrm{TM}}$ Fosmid Library Production Kit, epicentre ${ }^{\circledR}$ ) using the High-Speed Plasmid Mini Kit (Geneaid, New Taipei City, Taiwan) according to manufacturer's instruction. Isolated fosmids were sequenced starting from the $<$ TET-1 $>$ insertion using the TET-1 FP-1 forward and TET-1 RP-1 reverse primers (see manual of the EZTn $5^{\mathrm{TM}}<$ TET-1 $>$ Insertion Kit, epicentre ${ }^{\circledR}$ ) to identify the exact insertion position. Selected clones were tested for their RubisCO activities.

\section{RubisCO Activity Assay}

For RubisCO activity measurements double transposon clones were cultivated at $28^{\circ} \mathrm{C}$ on $200 \mathrm{ml}$ pre-heated $\mathrm{LB}$ medium supplemented with chloramphenicol $\left(12.5 \mu \mathrm{g} \mathrm{ml}^{-1}\right)$, kanamycin (50 $\left.\mu \mathrm{g} \mathrm{ml}^{-1}\right)$, tetracycline $\left(10 \mu \mathrm{g} \mathrm{ml}^{-1}\right)$, and autoinduction solution [1x final concentration (epicentre ${ }^{\circledR}$ )] in 11 flasks with shaking $(130 \mathrm{rpm})$ and harvested after $18 \mathrm{~h}$ by centrifugation $\left(9,800 \times g, 10 \mathrm{~min}\right.$, and $\left.4^{\circ} \mathrm{C}\right)$. Subsequently crude extracts were prepared. For this purpose, cell pellets were washed twice with buffer A [100 mM Tris- $\mathrm{HCl}$ ( $\mathrm{pH} 7.8), 10 \mathrm{mM} \mathrm{MgCl}_{2}$, $1 \mathrm{mM}$ EDTA, $25 \mathrm{mM} \mathrm{NaHCO} 3$ and $1 \mathrm{mM}$ DTT] before resuspension in $2 \mathrm{ml}$ of the same buffer. Cells were disrupted by the French pressure cell press method, followed by centrifugation $\left(19,580 \times g, 20 \mathrm{~min}\right.$, and $\left.4^{\circ} \mathrm{C}\right)$, as described before (Böhnke and Perner, 2015). The generated crude extracts were finally used as template to perform the RubisCO activity assay, where the concentrations of the reactant (RuBP) and the product (3PGA) of RubisCO reaction were quantified over time using High-Performance Liquid Chromatography (HPLC) (Böhnke and Perner, 2015). At least two biological replicates and three 
technical replicates were used for the RubisCO activity assay. Mean values of technical replicates were used to calculate the overall mean. Errors of RubisCO activity measurements were calculated with the Gaussian propagation of error. Standard derivations of technical replicates were propagated forward and are thus entered into the equation. Significant differences were calculated using an unpaired $t$-test with equal variance and two-tailed distribution. For each performed HPLC run different controls were tested additionally to the measured samples. The crude extract of the metagenome derived fosmid clone $71 \mathrm{C} 2$ containing the RubisCO gene cluster ( $c b b O-m Q-m M$ lysR2 lysR1 cbbLSQ-1O-1) and $22.2 \mathrm{~kb}$ flanking DNA serves as positive control and the crude extract of an E. coli fosmid clone without RubisCO genes encoded on its fosmid insert serves as a negative control. A protein free reference sample with $5 \mathrm{mM} \mathrm{RuBP}$ and $5 \mathrm{mM}$ 3-PGA dissolved in buffer A were furthermore applied through the assay and used (i) for sample peak assignment and (ii) to gather the non-enzymatic degradation of educts and products. The latter was used to calculate the pseudo-activity which is subtracted from each sample activity.

\section{Quantitative Reverse Transcriptase PCR}

Clones were cultivated in $100 \mathrm{ml}$ flasks on $20 \mathrm{ml} \mathrm{LB}$ media supplemented with autoinduction solution $[1 \mathrm{x}$ final concentration (epicentre $\left.\left.{ }^{\circledast}\right)\right]$ and the following antibiotics: chloramphenicol $\left(12.5 \mu \mathrm{g} \mathrm{ml}^{-1}\right)$ for the fosmid subclone 71C2II, chloramphenicol $\left(12.5 \mu \mathrm{g} \mathrm{ml}^{-1}\right)$ and kanamycin $(50 \mu \mathrm{g}$ $\left.\mathrm{ml}^{-1}\right)$ for transposon clones 22II $(\Delta c b b M)$, 24II $(\Delta c b b L), 6 \mathrm{II}$ $(\Delta l y s R 1)$, and 149II $(\Delta l y s R 2)$, and chloramphenicol $(12.5 \mu \mathrm{g}$ $\left.\mathrm{ml}^{-1}\right)$, kanamycin $\left(50 \mu \mathrm{g} \mathrm{ml}{ }^{-1}\right)$, and tetracycline $(10 \mu \mathrm{g}$ $\left.\mathrm{ml}^{-1}\right)$ for the double transposon clones 22II2B2 $(\Delta c b b M$ $\Delta l y s R 1), 22 \mathrm{II} 3 \mathrm{~A} 3(\Delta c b b M \Delta l y s R 2), 24 \mathrm{II} 1 \mathrm{H} 1(\Delta c b b L \Delta l y s R 1)$, and $24 \mathrm{II} 1 \mathrm{H} 7(\Delta c b b L \quad \Delta l y s R 2)$. Cultures were allowed to grow until an optical density $(\lambda=600 \mathrm{~nm})$ between 2.0 and 3.0 was reached [for clone 6II $(\Delta l y s R 1) 24 \mathrm{~h}$, all other clones $16 \mathrm{~h}$ ]. Total RNA was isolated with the UltraClean ${ }^{\circledR}$ Microbial RNA Isolation Kit (MO BIO Laboratories, Inc., Carlsbad, CA, United States) according to manufacturer's instructions with the exception that only $1 \mathrm{ml}$ cell culture was harvested instead of the recommended $2 \mathrm{ml}$. Subsequently, genomic DNA was removed by using the RTS DNase ${ }^{\mathrm{TM}}$ Kit (MO BIO Laboratories, Inc.) following the provided protocol, but with the modification that after half an hour an additional microliter RTS DNase was added. The reaction was incubated at $37^{\circ} \mathrm{C}$ for further 30 min followed by RTS DNA removal using $10 \mu \mathrm{l}$ instead of $5 \mu \mathrm{l}$ RTS DNase removal resins. One thousand two hundred microgram isolated RNA was used to synthesize cDNA with Invitrogen's SuperScript ${ }^{\circledR}$ VILO $^{\text {TM }}$ cDNA Synthesis Kit (Life Technologies ${ }^{\mathrm{TM}}$, Darmstadt, Germany), according to manufacturer's instructions. The generated cDNA was used to examine the fold change of RubisCO form I ( $c b b L)$ and form II $(c b b M)$ structural genes during expression in above mentioned transposon and double transposon clones relative to the intact version 71C2II. The expression data were normalized to the transcripts of three different genes, namely (i) the chloramphenicol-acetyltransferase (cat) gene, which is encoded on the fosmid vector and reflects its copy number, (ii) the
RNA polymerase sigma factor $r p o D$, which is a housekeeping gene, and (iii) the $16 \mathrm{~S}$ rRNA encoding gene. For this purpose, cDNA was diluted 1-10 and the cDNA that was derived from transcripts was used as a template for the amplification of $c b b L$ and $c b b M$ genes as well as the three different housekeeping genes. The SYBR ${ }^{\circledR}$ Select Master Mix, CFX (Applied Biosystems ${ }^{\circledR}$ by Life Technologies ${ }^{\mathrm{TM}}$ ) and the following primer pairs were used: for (i) $c b b L$ - cbbL_810F and cbbL_1115R, for (ii) $c b b M-$ cbbM_647F and cbbM_976R, for (iii) cat - ChlR_821F and ChlR_1104R, for (iv) rpoD - rpoD_416F and rpoD_720R, and for (v) the 16S rRNA gene - 16S_280F and 16S_564R (for details on primer characteristics see Table 2). The qRT-PCR on the MJ Mini ${ }^{\mathrm{TM}}$ Gradient Thermal Cycler (Bio-Rad, Hercules, CA, United States) was performed under the following conditions: $95^{\circ} \mathrm{C}$ for $2 \mathrm{~min}$ followed by 40 cycles of $98^{\circ} \mathrm{C}$ for $15 \mathrm{~s}, 51^{\circ} \mathrm{C}$ for $20 \mathrm{~s}$, and $72^{\circ} \mathrm{C}$ for $30 \mathrm{~s}$. Each run contains, next to the samples, various controls like (i) the non-template controls, (ii) the no reverse transcriptase control as well as (iii) an inter run calibrator to ensure comparability between different runs, i.e., one reaction from the previous plate was repeated on the new plate. At least two biological and three technical replicates were measured and used to calculate fold changes $\left(2^{-\Delta \Delta \mathrm{Ct}}\right)$. Technical replicates were arithmetically averaged and resulting mean values were used to calculate an overall mean. Errors were calculated with the Gaussian propagation of error. Standard derivations of technical replicates were entered into the equation and thus propagated forward. Significant differences were calculated from $\log$ transformed values using an unpaired $t$-test with equal variance and two-tailed distribution.

\section{Polar Effects}

Polar effects were investigated to determine whether transposon insertions have an impact on transcript abundances of genes located downstream of an insertion site. Therefore, transcript abundances of genes located downstream of $c b b M$ and $c b b L$ were measured for $\Delta c b b M$ (22II) and for $\Delta c b b L$ (24II), and compared with the transcript abundances in the intact version 71C2II. Investigated genes were (i) $c b b O-m$ and (ii) $c b b Q-m$ in $\triangle c b b M$ and (iii) $c b b Q-1$ and (iv) $c b b O-1$ in $\triangle c b b L$. The cDNA used as template was the same as that isolated before for qRTPCR of $c b b L$ and $c b b M$. The qRT-PCR conditions were the same as mentioned above for the amplification of $c b b L$ and $c b b M$, but with different primers: (i) $c b b O-m$ - cbbO-m_700F and cbbO$\mathrm{m} \_922 \mathrm{R}$, for (ii) $c b b Q-m-$ cbbQ-m_2828F and cbbQ- $\_$2974R, for (iii) $c b b Q-1$ - cbbQ-1_9714F and cbbQ-1_9912R, and for (iv) cbbO-1 - cbbO-1_11263F and cbbO-1_12525R (for details on primer characteristics see Table 2). Three biological and three technical replicates were measured and used to calculate fold changes $\left(2^{-\Delta \Delta C t}\right)$. Statistics were calculated in the same way as has been described for qRT-PCR data of $c b b L$ and $c b b M$.

\section{Overexpression and Protein Purification}

The four genes encoding CbbL, CbbM, LysR1, and LysR2 were cloned in the expression vector pet21a (Novagen/Merck, Darmstadt, Germany). The coding regions of the targeted genes were amplified from the fosmid DNA of the metagenome derived clone $71 \mathrm{C} 2$, whereby restriction sites for NheI and 
TABLE 2 | Primers used in this study.

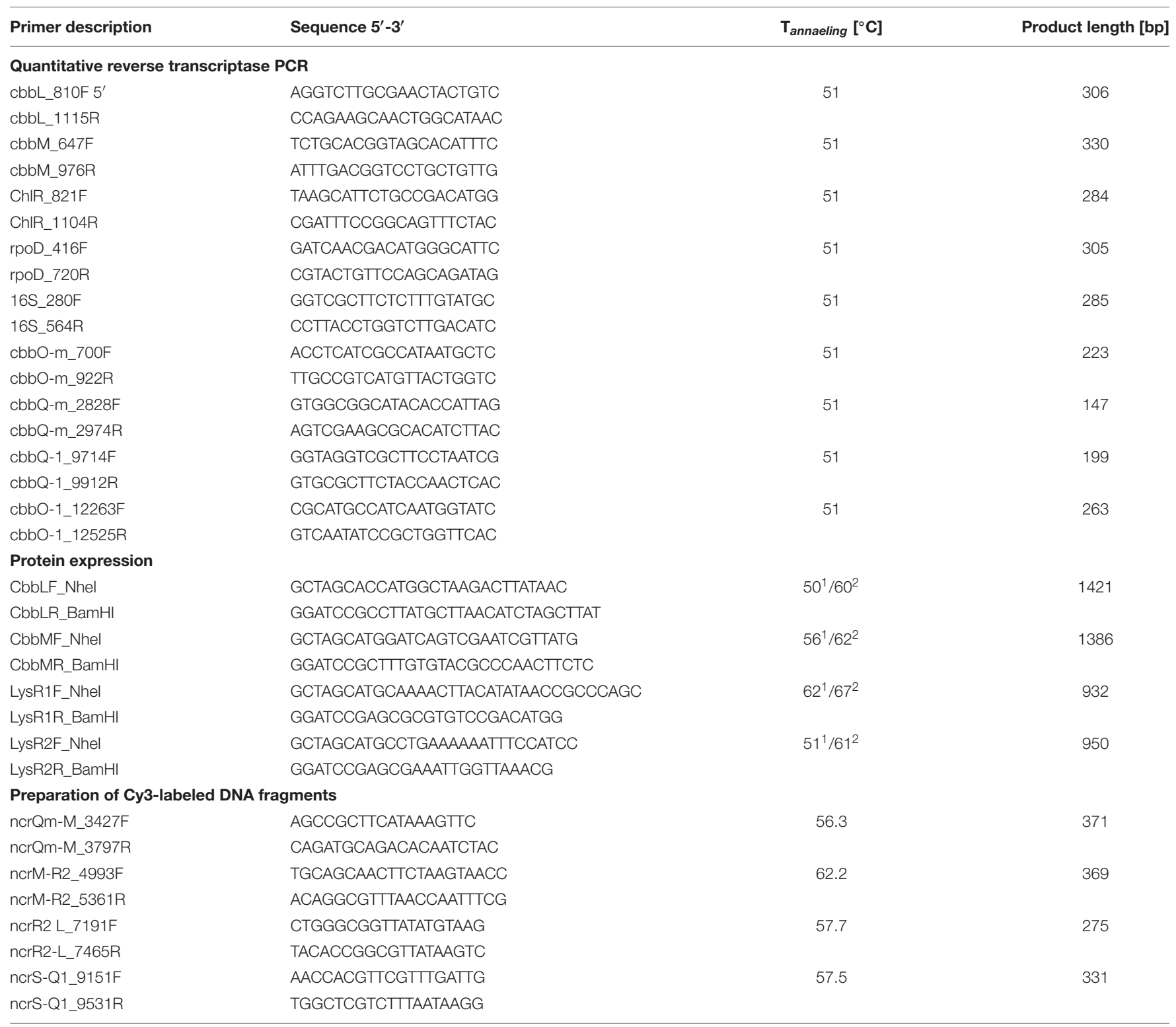

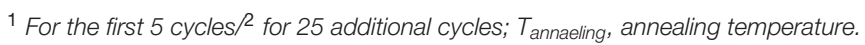

BamHI were inserted using following primer pairs: (i) for $c b b L$ - CbbLF_NheI and CbbLR_BamHI, (ii) for $c b b M$ cbbMF_NheI and cbbMR_BamH1, (iii) for lysR1 - LysR1F_NheI and LysR1R_BamHI, and (iv) for lysR2 - LysR2F_NheI 5' - and LysR2R_BamHI (primer sequences, annealing temperatures and product length are listed in Table 2). Amplification was done with the Pfu DNA Polymerase (Thermo Fisher Scientific, Waltham, MA, United States), following manufacturer's instructions. The amplified fragments were ligated in the pet21a expression vector (Novagen/Merck) using the previously inserted restriction sites (NheI and BamHI). This vector has a His-tag coding sequence for the C-terminus of the cloned protein. The constructed plasmids (i) pet21a:: $c b b L$, (ii) pet21a::cbbM, (iii) pet21a::lysR1, and (iv) pet21a::lysR2 were transformed into E. coli Rosetta-gami2 host strains. Verified clones were cultured at $17^{\circ} \mathrm{C}(\mathrm{CbbM})$ or at $22^{\circ} \mathrm{C}$ (CbbL, LysR1, and LysR2) in $200 \mathrm{ml} \mathrm{LB}$ supplemented with ampicillin $\left(100 \mu \mathrm{g} \mathrm{ml}^{-1}\right)$, tetracycline $\left(10 \mu \mathrm{g} \mathrm{ml}^{-1}\right)$, and chloramphenicol $\left(12.5 \mu \mathrm{g} \mathrm{ml}^{-1}\right)$ to an optical density $(\lambda=600 \mathrm{~nm})$ of $0.7-0.8$. IPTG was added to a final concentration of $0.1 \mathrm{mM}$ for CbbL, $1 \mathrm{mM}$ for CbbM, $1 \mathrm{mM}$ for LysR1, and $0.1 \mathrm{mM}$ for LysR2. The cultures were then grown over night at $17^{\circ} \mathrm{C}(\mathrm{CbbM})$ or at $22^{\circ} \mathrm{C}(\mathrm{CbbL}$, LysR1, and LysR2). Cells were harvested by centrifugation $\left(7,600 \times g, 8 \mathrm{~min}\right.$, and $\left.8^{\circ} \mathrm{C}\right)$ and washed twice with 1x PBS buffer $(137 \mathrm{mM} \mathrm{NaCl}, 2.7 \mathrm{mM} \mathrm{KCl}$, $10 \mathrm{mM} \mathrm{Na}_{2} \mathrm{HPO}_{4}$, and $2 \mathrm{mM} \mathrm{KH}_{2} \mathrm{PO}_{4}, \mathrm{pH}=7.4$ ). Cell pellets were stored at $-20^{\circ} \mathrm{C}$ until proceeding with His-tag purification using Ni-NTA agarose (Qiagen, Hilden, Germany) as described in protocol 14 of TheQiaexpressionist (Qiagen, 2003), with some 
modifications: Initially cell pellets were resuspended in $2 \mathrm{ml}$ lysis buffer (containing $10 \mathrm{mM}$ imidazole). Each lysate was passed through the French press in order to disrupt cells. Cellular debris were removed by centrifugation $\left(19,580 \times \mathrm{g}, 20 \mathrm{~min}\right.$, and $\left.4^{\circ} \mathrm{C}\right)$ and supernatant volumes were brought to $20 \mathrm{ml}$ with lysis buffer. Afterward $2 \mathrm{ml}$ Ni-NTA agarose was added to the diluted lysates, which were incubated for $2 \mathrm{~h}$ on ice (shaking). After pelleting $\left(1,000 \times g, 30 \mathrm{~s}\right.$, and $\left.8^{\circ} \mathrm{C}\right) \mathrm{Ni}-\mathrm{NTA}$ resins were washed twice with washing buffer (containing $20 \mathrm{mM}$ imidazole). The protein was eluted from the column with five volumes of elution buffer (containing $250 \mathrm{mM}$ imidazole). The concentration of the total purified protein was measured by performing the Bradford assay as described previously (Bradford and Williams, 1976) using bovine serum albumin as a standard. The proteins were further analyzed by SDS polyacrylamide gel electrophoresis using 12\% (w/v) gels and Western-immunoblotting using 6-His-specific antibodies (see Supplementary Figure 1).

\section{Preparation of Cy3-Labeled DNA Fragments}

In preparation for the mobility shift assay four non-coding regions located within the metagenome derived RubisCO gene cluster were Cy3-labeled, namely the non-coding regions between: (i) $c b b Q-m$ and $c b b M$, (ii) $c b b M$ and $l y s R 2$, (iii) $l y s R 1$ and $c b b L$ as well as (iv) $c b b S$ and $c b b Q-1$. Labeling was done during amplification using Cy3-labeled dCTP's (1 mM, GE Healthcare, Little Chalfont, United Kingdom), a mixture of dATP, dTTP, and dGTP (2 mM), the Phusion DNA Polymerase (Thermo Fisher Scientific) and the following primer pairs: (i) ncrQm-M_3427F and ncrQm-M_3797R for the non-coding region between $c b b Q-m$ and $c b b M$, (ii) ncrM-R2_4993F and ncrM-R2_5361R for the non-coding region between cbbM and lysR2, (iii) ncrR1-L_7191F and ncrR1-L_7465R for the non-coding region between $l y s R 1$ and $c b b L$, and (iv) ncrS-Q1_9151F and ncrS-Q1_9531R for the non-coding region between $c b b S$ and $c b b Q-1$ (see Table 2 for primer sequences). PCR conditions were: Denaturation at $98^{\circ} \mathrm{C}$ for $10 \mathrm{~s}$, primer annealing for $30 \mathrm{~s}$ at appropriated annealing temperatures (see Table 2), and elongation at $72^{\circ} \mathrm{C}$ for $12 \mathrm{~s}$ ( 32 cycles).

\section{Electrophoretic Mobility Shift Assay (EMSA)}

The mobility shift assay was based on a previously published protocol (Charoenpanich et al., 2013) but with modifications: Purified $\mathrm{His}_{6}-\mathrm{CbbL}, \mathrm{His}_{6}-\mathrm{CbbM}$, His 6 -LysR1, and His ${ }_{6}$-LysR2 were investigated for the ability to bind at the four non-coding regions amplified from the metagenome derived RubisCO gene cluster. For this purpose, proteins were tested (i) individually but also (ii) pairwise in combination with each other. The protein concentrations used for approaches with individual proteins ranged from 0 to $1,000 \mathrm{ng}$ per $30 \mu \mathrm{l}$ reaction mixture. For approaches with two different proteins up to 2,000 ng total protein per $30 \mu \mathrm{l}$ were used in one reaction, which corresponds to a maximum of 1,000 ng of each protein and thus ensures the comparability with the single protein approaches. Regardless of whether one or two proteins were used for the assay, protein(s) was/were firstly incubated with a total of $200 \mathrm{ng}$ salmon sperm DNA for $5 \mathrm{~min}$ at room temperature in binding buffer $(50 \mathrm{mM}$ Tris- $\mathrm{HCl}, 250 \mathrm{mM} \mathrm{KCl}, \mathrm{pH}=8.5)$ to prevent unspecific DNA shifts. After this Cy3-labeled DNA fragments were added (200 ng per $30 \mu \mathrm{l}$ reaction) and reaction mixture was incubated at room temperature in the dark for further $20 \mathrm{~min}$. Subsequently $5 \mu \mathrm{l}$ loading dye (20\% TBE buffer and $80 \%$ glycerol) was added and samples were loaded on a 5\% TBE-polyacrylamide gel. Following electrophoresis at $50 \mathrm{mV}$ for $3 \mathrm{~h}$ in cooled TBE-buffer, gels were visualized on a VersaDoc ${ }^{\mathrm{TM}} \mathrm{MP} 4000$ (Bio-Rad) at $550 \mathrm{~nm}$ and an exposure time of $300 \mathrm{~ms}$.

\section{Computational Analyses}

Distinct regulatory features were predicted for the DNA of the metagenome derived RubisCO gene cluster using different online tools. Promoter regions were predicted for all non-coding regions with the SoftBerry program BProm (Solovyev and Salamov, 2011). We also searched for inverted repeats, which are putatively able to fold into stem-loop structures using Emboss Palindrome (Rice et al., 2000), with a minimum length for repeats of 8 nt and a maximum gap between repeated elements of $100 \mathrm{nt}$. With respect to the formation of stem-loop structures, inverted repeats with loops less than three bases were not taken into account, because they are thought to be sterically impossible and thus are believed not to be formed (Bon and Orland, 2011). LysR binding sites were identified manually by searching for the typical LysR binding motif TnA-n7/8-AnT which has been identified in other RubisCO harboring organisms before (van Keulen et al., 2003; Maddocks and Oyston, 2008 and references therein).

\section{RESULTS}

To understand the processes involved in expression of a fully active RubisCO form I (CbbLS) and form II (CbbM) enzyme, we constructed two double mutant libraries using a $13 \mathrm{~kb}$ metagenomic fragment encoding the RubisCO gene cluster. In one case, the $\triangle c b b M$ fragment of transposon clone 22II, and in the other case, the $\Delta c b b L$ fragment of transposon clone 24II provided the base for the second mutant library. These double mutants were used to study how gene deletions influence $c b b L$ and $c b b M$ transcription and respective enzyme activities. We also searched through the metagenomic DNA sequence in silico for putative LysR binding sites, promoter regions or structures capable of forming stem-loops - possibly affecting transcription and determined experimentally whether RubisCO and LysR proteins and protein combinations bind to non-coding regions in the metagenomic fragment.

\section{$c b b L$ and $c b b M$ Transcription after Gene Deletions}

$c b b L$ and $c b b M$ transcription abundances were tested for eight mutants and normalized to three different reference genes (cat, rpoD, and 16S rRNA) (Figure 1). Generally, transcript levels of $c b b L$ in $\triangle c b b M$ and of $c b b M$ in $\triangle c b b L$ remained unchanged relative to the undeleted metagenomic fragment (71C2II). 


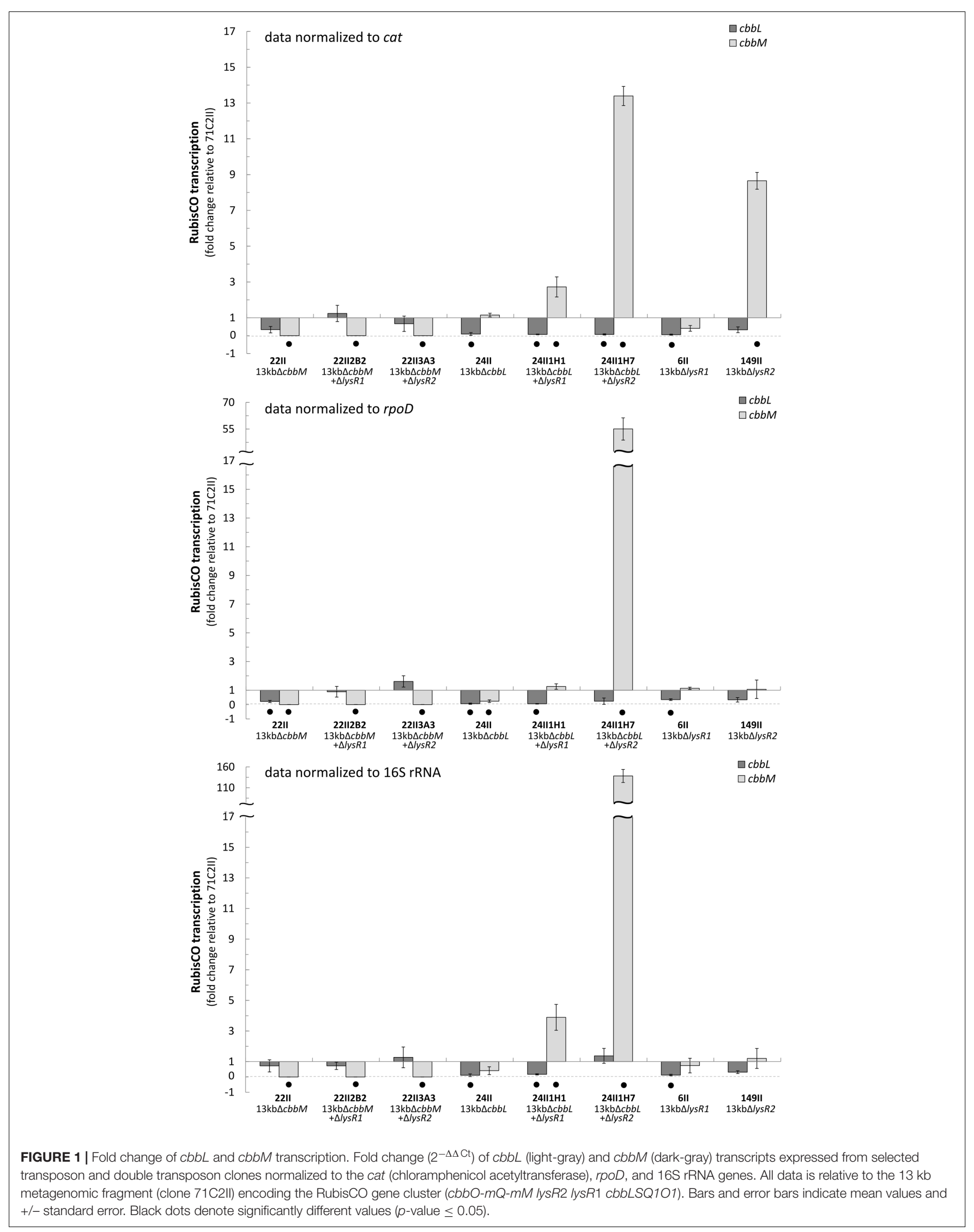


$c b b L$ gene transcription was only significantly downregulated in $\Delta l y s R 1$ if $c b b M$ was expressed, since no changes in $c b b L$ transcript levels were observed in $\Delta l y s R 1 \Delta c b b M$. In contrast, $c b b M$ gene transcription was significantly upregulated in $\triangle c b b L \quad \Delta l y s R 1$ double transposon clone 24II1H1 (3-fold) and in $\triangle c b b L \quad \Delta l y s R 2$ double transposon clone $24 \mathrm{II} 1 \mathrm{H} 7$ (15-fold).

\section{$c b b L$ and $c b b M$ Activity after Gene Deletions}

All RubisCO activities of clones from the double mutant libraries where either $\Delta c b b M$ (22II) or $\Delta c b b L$ (24II) was used for the construction of the double mutants can be viewed in Figures 2A,B, respectively. Total RubisCO activity of the undeleted $13 \mathrm{~kb}$ fragment (71C2II) increased considerably in $\triangle c b b M$ (22II) (5-fold). Additional deletions in lysR1, lysR2, cbbQ$m$, and $c b b O-m$ resulted in a significant decrease of RubisCO activity.

Total RubisCO activity of the undeleted $13 \mathrm{~kb}$ fragment (71C2II) was significantly reduced in $\triangle c b b L$ (24II). When additionally deleting lysR2 (24II1H7), the RubisCO activity increased (3.5-fold), restoring the original activity of clone 71C2II. In four of the tested double mutant $\triangle c b b L$ clones the RubisCO activity was considerably reduced. These were clone 24II1G2, where parts of the intergenic region of $c b b M$ and lysR2 were deleted, clone 24II2G1, where parts of the non-coding region between $c b b S$ and $c b b Q-1$ were deleted, and the two $\Delta c b b L \Delta c b b Q-1$ clones (24II6H6 and 24II5G11). As expected, no RubisCO activity was measured for $\triangle c b b L$ $\Delta c b b M$.

\section{Putative Promoters, LysR Binding Sites and Stem-Loop Forming Structures}

We searched the intergenic regions of our metagenomic fragment for structures which encode putative promoter regions that provide potential LysR binding sites or that may form stem-loops (Figure 3). We found 6 putative promoter binding sites, 15 putative LysR binding sites, and 18 putative stem-loop forming structures (for exact positions on the metagenomic fragment see Supplementary Figure 2).

We also performed mobility shift assays to test whether LysR1, LysR2, CbbL, and CbbM or a combination of these proteins bind to the non-coding regions $c b b Q-m$ and $c b b M, c b b M$ and lysR2, lysR1 and $c b b L$ or $c b b S$ and $c b b Q-1$ (Figure 4). LysR1 binds to all tested non-coding regions (Figure 4A). Its binding ability is enhanced for the intergenic region lysR1 and $c b b L$ if CbbL or LysR2 are additionally present (Figure 4B). LysR2 alone appears to only bind to two non-coding regions: between $c b b Q-m$ and $c b b M$ and between $c b b M$ and $l y s R 2$ (Figure 4A). $\mathrm{CbbM}$ addition intensifies the binding ability to the $c b b M$ and lysR2 intergenic region (Figure 4B). The presence of CbbM also enables LysR2 to bind to two further non-coding regions, namely lysR 1 and $c b b L$ as well as $c b b S$ and $c b b Q-1$ (Figure 4B). Other protein combinations likely reflect binding of one of the proteins alone.

\section{DISCUSSION}

\section{Possible CbbL Expression and Regulation}

In the intergenic region of lysR 1 and $c b b L$ two promoters were predicted: (i) one could be for $c b b L$ transcription (with the -10 box 'AGGAATCAT' at position 7,271 bp and the -35 box 'TTGATA' at position 7,250 bp) and (ii) the other for lysR1/lysR2 transcription with the -10 box at position 7,275 bp 'ATCATATAC' and with the -35 box at position 7,302 bp 'TAACAA' (Supplementary Figure 2). This is in line with previous predicted functions for the non-coding region between $l y s R$ and $c b b L$ in other organisms, where promoters for both directions were identified (Kusano and Sugawara, 1993; Wei et al., 2004). Additionally, three and two putative LTTR binding sites upstream of the putative $c b b L$ and lysR1/lysR2 promoters, respectively, were recognized (Figure 3). These sites may be involved in LysR1 and/or LysR2 regulated $c b b L$ transcription as well as autoregulation of their own transcription, as has been commonly demonstrated for enzymes of the LysR family (Schell, 1993; Maddocks and Oyston, 2008). The mobility shift assay verified that binding sites are located in this non-coding region (Figure 4). Here, DNA binding of LysR1 is intensified by the presence of LysR2 or CbbL (Figure 4B). LysR2 is also capable of binding to this region, but only when CbbM proteins are available. Promiscuous heterotypic interactions between different LTTRs in E. coli have been shown before, but the relevance of such cross-interactions remains unknown (Knapp and $\mathrm{Hu}, 2010$ ). However, since our experiment showed that LysR1's DNA binding ability is increased by LysR2, one may conclude that LysR1 and LysR2 are also able to cross-interact and form heteromultimers with its non-cognate partner. The heteromultimer (LysR1+LysR2) may cause different regulatory effects relative to the homomultimers (LysR1+LysR1 or LysR2+LysR2). The role that CbbL and CbbM play for intensified LysR binding currently remains unclear but may be related to DNA or RNA stability. Mobility shift assays with RNA and the large RubisCO subunit of Chlamydomonas reinhardtii demonstrated CbbL's ability to bind to RNA in a sequenceindependent manner under certain conditions (Yosef et al., 2004).

Although $c b b L$ transcription levels remained unchanged in $\triangle c b b M \quad \Delta l y s R 1$ and $\triangle c b b M \Delta l y s R 2$ (Figure 1), these clones exhibited reduced CbbL activity (Figure 2A). This discrepancy may be explained if LysR proteins also act on the transcription of genes encoding proteins, which influence CbbL activity. Likely candidates encoded on this metagenomic fragment are CbbO-m, CbbQ-m, CbbQ-1, and CbbO-1, previously shown to be involved in post-translational activation of RubisCO enzymes (Tsai et al., 2015). Indeed LysR1 proteins are demonstrated to bind upstream of $c b b Q-m / c b b O-m$ and $c b b Q-1 / c b b O-1$ regions (Figure 4A). LysR2 can also bind upstream of $c b b Q-m / c b b O-m$ and if CbbM is present can bind upstream of $c b b Q-1 / c b b O-1$, too (Figures 4A,B, respectively). While the deletion of $c b b Q-m$ and $c b b O-m$ in $\triangle c b b M$ illustrated a RubisCO activity loss, CbbQ-1 and CbbO-1 did not have an effect on CbbL activity (Figure 2A). Based 

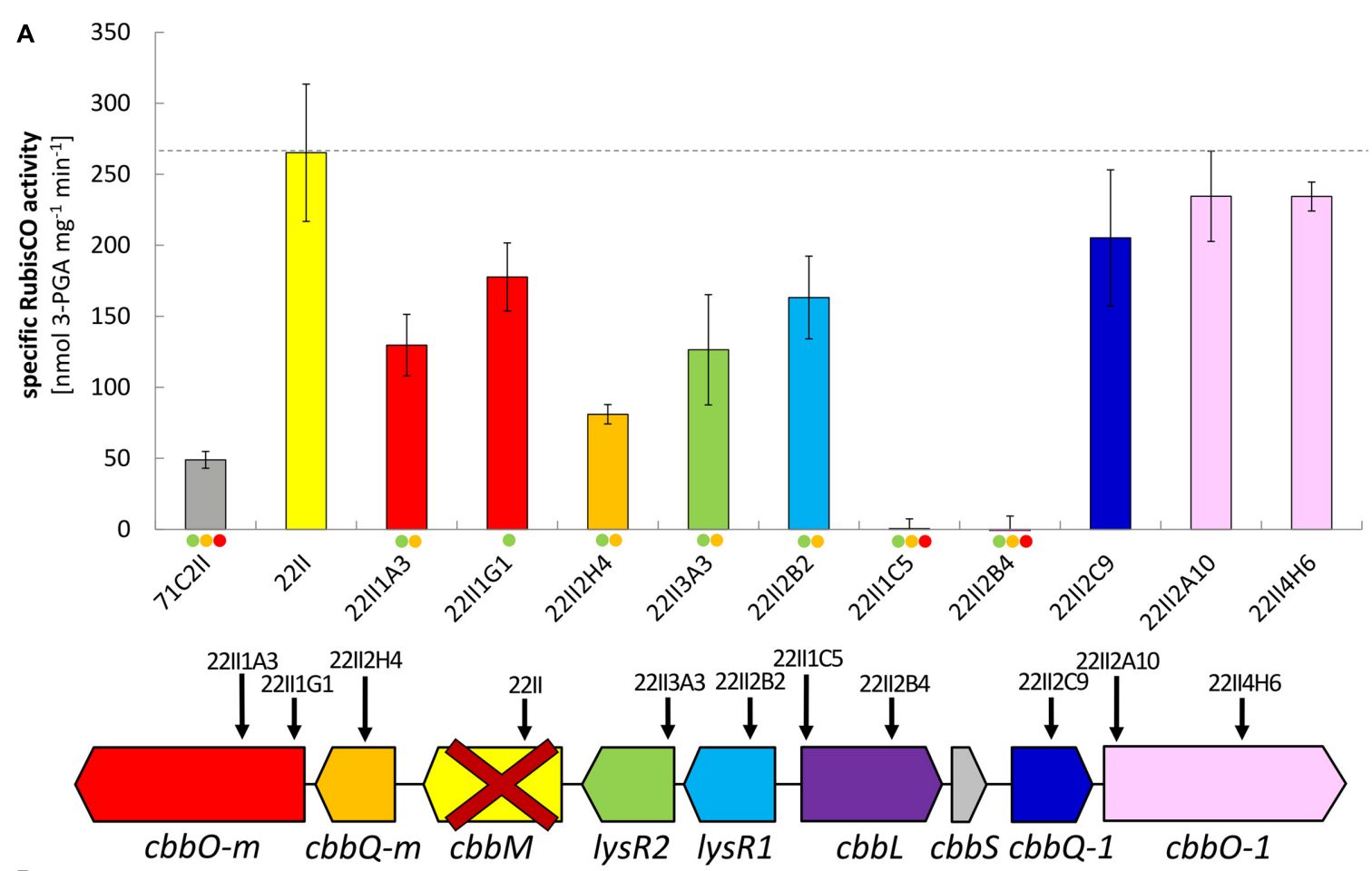

B

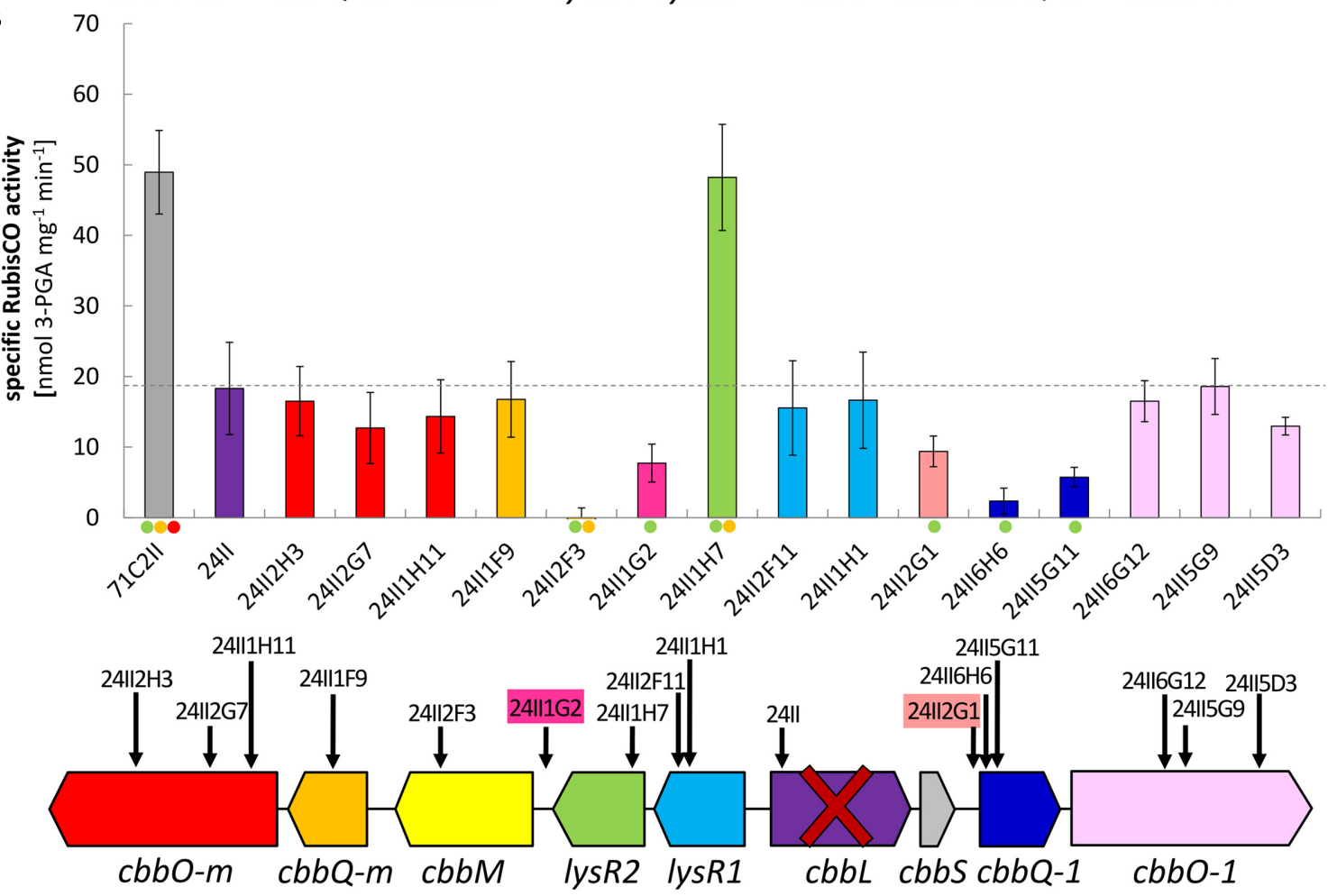

FIGURE 2 | Specific RubisCO activities and insertion positions of tested double transposon clones. Specific RubisCO activities and schematic gene arrangement of (A) double transposon clones constructed on the basis of the $\triangle c b b M$ transposon clone 22ll and (B) double transposon clones constructed on the basis of the $\triangle c b b L$ transposon clone 24II. Identified open reading frames (ORFs) are indicated as arrows in the direction of transcription. Insertion sites are denoted by vertical black arrows and transposon clone numbers. Genes are color coded according to the bars indicating corresponding RubisCO activity. Gene abbreviations are as follows: $c b b O-m$ - von Willebrand factor type A; $c b b Q-m$ - ATPase AAA-type; $c b b M$ - ribulose-1,5-bisphosphate carboxylase/oxygenase large subunit, form II; lysR2 - transcriptional regulator, LysR family; lysR1 - transcriptional regulator, LysR family; cbbL - ribulose-1,5-bisphosphate carboxylase/oxygenase large subunit, form I; cbbS - ribulose-1,5-bisphosphate carboxylase small subunit; cbbQ-1 - ATPase, AAA-type; cbbO-1 - von Willebrand factor. Bars and error bars indicate mean values and $+/$ - standard error. The level of significant differences is denoted by dots where green is $\leq 0.05$, yellow is $\leq 0.01$, and red is $\leq 0.001$. 


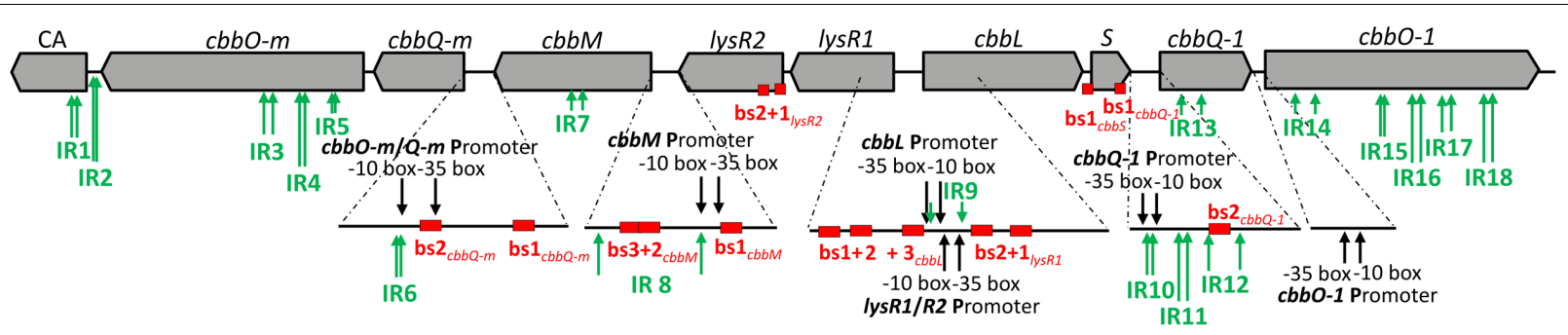

FIGURE 3 | Regulatory features predicted for the DNA of the metagenome derived RubisCO gene cluster. ORFs are displayed as gray arrows in the direction of transcription. The same gene abbreviations as specified in Figure $\mathbf{2}$ are used. Predicted promoters are indicated by black arrows, inverted repeats (IR) are denoted by green arrows and putative LysR binding sites (bs) are represented by red boxes.

on the available information, we posit that CbbQ-m/CbbO-m activates CbbL and that LysR1 and LysR2 proteins promote CbbQ-m/CbbO-m expression (compare model in Figure 5).

Intriguingly, CbbM also appears to play a role for $c b b L$ expression, which has not been observed in any other study before. The deletion of $c b b M$ leads to a 5-fold RubisCO activity increase (Figure 2A) indicative of CbbM's repressive nature for $c b b L$ expression. However, in $\triangle c b b M c b b L$ transcript levels are not elevated (Figure 1). Possible scenarios include that CbbM scavenges post-translational activators (CbbQ-m/CbbO-m), which are then not available for CbbL activation or that CbbM is involved in repressing CbbQ-m/CbbO-m, which may be needed for $\mathrm{CbbL}$ activation (Figure 5). For information on putative polar effects for $c b b Q-m / c b b O-m$ transcript abundance caused by transposon insertion in the upstream neighboring $c b b M$ gene see Supplementary Results and Discussion and Supplementary Figure 3.

\section{Possible CbbM Expression and Regulation}

A putative promoter was identified upstream of $c b b M$ (Figure 3), confirming recent results indicative of $c b b M$ being transcribed alone in this fragment (Böhnke and Perner, 2015). In the intergenic region of $c b b M$ and $l y s R 2$ three putative LysR binding sites were predicted, two of which partially overlap ('LysR bs $1_{c b b M}$,' 'LysR bs $2 / 3_{c b b M}$,' see Supplementary Figure 2). In Xanthobacter flavus the same arrangement of a single LysR binding site followed by two overlapping binding sites, between a RubisCO structural gene and a LysR transcriptional regulator was also identified and all three sites were evidenced to be functional (van Keulen et al., 2003). In our fragment LysR binding sites upstream of $c b b M$ exist, which allow binding of LysR1 and LysR2 proteins (Figure 4A). LysR2 binding was even intensified if CbbM was present (compare Figure 4B). Upregulation of the $c b b M$ transcript (Figure 1) and increasing RubisCO activity in the double mutant $\triangle c b b L \quad \Delta l y s R 2$ (Figure 2B) strongly suggest that LysR2 acts as a repressor for $c b b M$ gene expression where CbbM itself contributes to intensified LysR binding ability and thus its own transcriptional regulation (Figure 5). The combination of CbbL and LysR1 also appears to result in a repressive $c b b M$ transcriptional regulation but single mutations in $c b b L$ and $l y s R 1$ did not cause upregulation of the $c b b M$ gene (see Figure 1). However, despite higher $c b b M$ transcript levels in $\Delta c b b L \Delta$ lysR1, this clone did not demonstrate an increase in RubisCO activity (Figure 2B), contrasting the transcriptional data at first glance. These results can be explained though if LysR1 also controls the expression of post-translational activators, which here only seems applicable if $\mathrm{CbbL}$ is also present. And indeed LysR1 appears to be able to bind upstream of $c b b Q-m / c b b Q-m$ and of $c b b Q-1 / c b b O-1$ (Figure 4), where also putative LysR binding sites were recognized (Figure 3). Of these likely post-translational activators only the deletion of cbbQ-1 caused a CbbM activity loss and thus makes its LysR regulated role in $\mathrm{CbbM}$ activation under the provided conditions highly likely. We thus suggest that CbbQ-1 activates CbbM and that LysR1 proteins may prevent CbbQ-1 expression if CbbL is present. Additionally, an insertion at position 9,463 bp, i.e., 15 bp upstream of the $c b b Q-1$ transcription start in the $\triangle c b b L$ clone $24 \mathrm{II}$, resulted in significantly reduced CbbM activity (see Figure 2B, clone 24II2G1). Even though this insertion is located downstream of putative regulatory features, the 1,674 bp comprising <TET> insertion represents a barrier the RNA polymerase most likely cannot simply overcome, which would result in an impaired $c b b Q-1$ transcription and thus no CbbQ-1 would be present. Unexpectedly, the deletion in $c b b O-1$, downstream of $c b b Q-1$, did not alter RubisCO activity (Figure 2B). However, the elevated number of inverted repeats (5/18 identified on the metagenomic fragment) in the cbbO-1 gene, which are theoretically capable of forming stemloop structures, may indicate some fine-tuned transcriptional regulation (Treangen et al., 2009 and references therein). Under the provided conditions $c b b O-1$ may be downregulated and under other environmental conditions may well be important for RubisCO activation.

In the intergenic region of $c b b M$ and lysR2 a large inverted repeat flanking $86 \mathrm{nt}$ (IR8, see Supplementary Figure 2) also exists. Such inverted repeats often form stem-loop structures that are important for controlling transcription initiation and termination, mRNA stabilization or genome plasticity (Treangen et al., 2009 and references therein). They also play roles in supporting DNA binding proteins in finding their binding sites (Frost et al., 1994). The IR8 in our metagenomic fragment may well represent such a signaling stem-loop structure that guides LysR to the LysR binding sites. An insertion of a tetracycline cassette in the left arm of the IR8 (clone 24II1G2), directly 


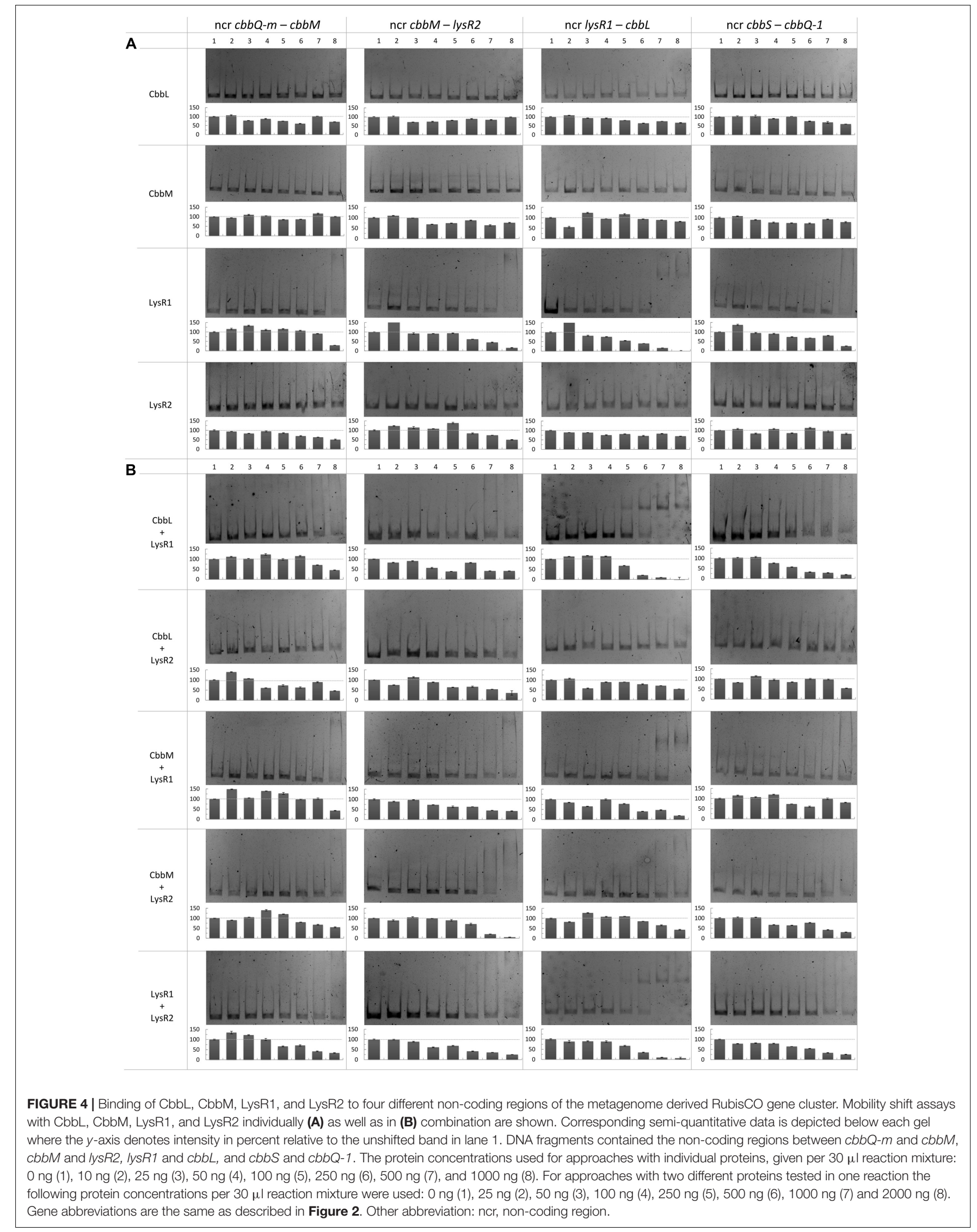




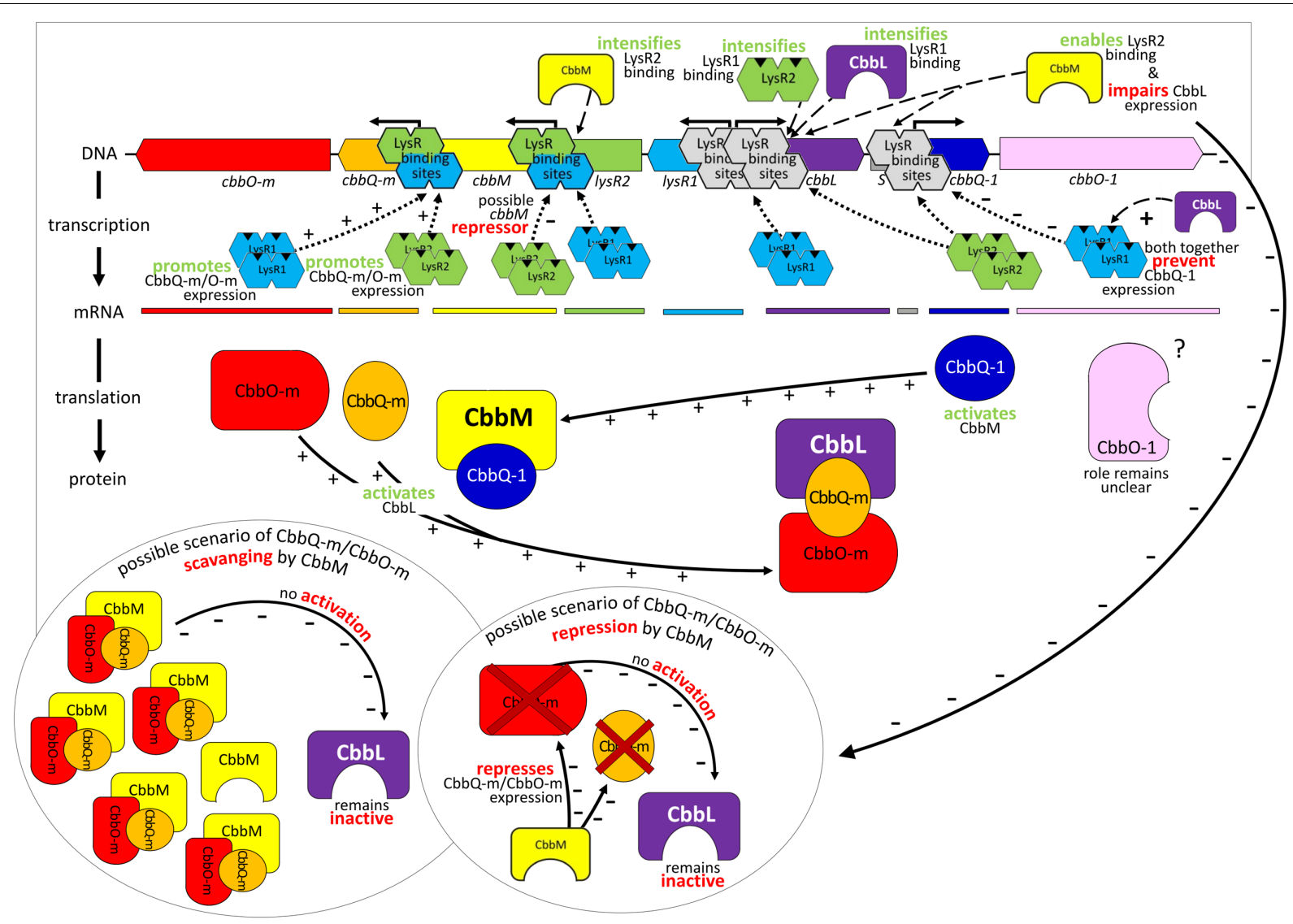

FIGURE 5 | Model of gene regulation and possible protein interaction. Relevant transcriptional and post-translational regulatory processes hypothesized for the $13 \mathrm{~kb}$ comprising metagenome derived RubisCO gene cluster. Identified genes are indicated as arrows in the direction of transcription and marked in the same color as the corresponding mRNA and resulting gene products. Abbreviations used are the same as described in Figure 2.

between the LysR binding sites 'bs1 $c b b M$ ' and 'bs $2 / 3_{c b b M}$ ' (see position 5,232 nt in Supplementary Figure 2) resulted in a significant RubisCO activity loss (Figure 2B). One explanation could be that this structure is necessary for the expression of a functional CbbM. Since this insertion also separates the putative -10 from the -35 promoter box, the RubisCO activity loss may be due to the impaired promoter region.

\section{Benefits and Drawbacks of Working with a Metagenomic Fragment in a Non-native System}

Restricting the work to culture-depended approaches, neglects the large majority of RubisCO gene clusters from uncultured organisms. However, working with metagenomes in non-native systems holds both promise and pitfalls. The benefits of using E. coli as a host organism are well-known: E. coli has an unrivaled fast growth on inexpensive media and the genetics are very well-known, making transformations with exogenous DNA simple and straightforward (Rosano and Ceccarelli, 2014). In contrast, expression of a metagenomic fragment in a surrogate host may also entail cross-talks, inhibitions and unspecific reactions. Recombinant gene expression in E. coli and other surrogate hosts might be troublesome due to, e.g., unrecognized intrinsic promotors and associated factors, a diverging codon usage or problems with correct protein folding (Perner et al., 2011).

One major advantage of working with a metagenomic fragment in fosmid clones (besides gaining access to the world of the unculturables) is its relatively small size (in this case: $13 \mathrm{~kb}$ metagenomic fragment). The small size infers clear gene arrangements and a limited number of possible gene and/or protein interactions relative to the (hardly tangible) complexity in a native system. The same work in a cultured representative is considerably more difficult and time consuming, because genes with yet unknown functions, which are not necessarily located in the vicinity of the gene cluster under investigation, may well participate in/contribute to the gene regulation and activation of the enzyme (indirectly), as has recently been shown for orf06 (Böhnke and Perner, 2015). Although the metagenomic approach with a defined number of genes can simplify first insights into regulatory mechanisms, it can also hinder the understanding of the mechanisms given that some vital genes/respective products cannot be expressed/synthesized as they are located on parts of the genome not present on the captured fraction of the metagenome. 
To overcome such limitations the use of a host with the genomic inventory to operate the CBB cycle may be a viable option. In our case a cultured Thiomicrospira strain could be used and the genes under investigation deleted. However, deleting gene clusters in $T$. crunogena which are comparable to our $13 \mathrm{~kb}$ metagenomic fragment and expressing the latter heterologously in the Thiomicrospira host or alternatively constructing double mutants as we did in our metagenomic fragment (i.e., nine deletions in $\triangle c b b L$ and eight deletions in $\Delta c b b M)$ to investigate regulatory mechanisms is hardly feasible, given that Thiomicrospira's genetic accessibility is not understood and thus any transformation with exogenous DNA becomes challenging. An alternative host that operates the $\mathrm{CBB}$ cycle and where mutations have been successfully constructed is $R$. capsulatus (Alphaproteobacteria) (Paoli et al., 1998; Witte et al., 2010; Dangel et al., 2014; Varaljay et al., 2016). However, this potential host encodes different types of RubisCOs and has other RubisCO gene cluster arrangements and likely different gene regulation mechanisms than the organism encoding our metagenomic fragment.

For future work one may consider combining studies in a genetically accessible surrogate host such as E. coli, naturally incapable of operating the $\mathrm{CBB}$ cycle, with subsequent investigations in a closely related cultured representative. Thus, the first insights of complex RubisCO regulatory mechanisms obtained through studies dealing with RubisCO gene expression in a non-native system could be used in further studies where, e.g., the role of external factors could be studied in a native system.

\section{CONCLUSION}

The intense interactions between the different proteins suggest the complex, but fine-tuned nature of the RubisCO regulatory machinery. This fine-tuned regulatory machinery reflects the highly dynamic nature of hydrothermal vent environments from which this metagenomic fragment was extracted. Albeit the $\mathrm{CBB}$ cycle has a much higher energy requirement than other autotrophic $\mathrm{CO}_{2}$ fixation pathways (Berg et al., 2010), it can operate when $\mathrm{O}_{2}$ is present, while many enzymes of other $\mathrm{CO}_{2}$ fixation pathways are highly $\mathrm{O}_{2}$ sensitive (Berg, 2011).

\section{REFERENCES}

Amann, R. I., Ludwig, W., and Schleifer, K. H. (1995). Phylogenetic identification and in situ detection of individual microbial cells without cultivation. Microbiol. Rev. 59, 143-169.

Axler-DiPerte, G. L., Miller, V. L., and Darwin, A. J. (2006). YtxR, a conserved LysR-like regulator that induces expression of genes encoding a putative ADPribosyltransferase toxin homologue in Yersinia enterocolitica. J. Bacteriol. 188, 8033-8043. doi: 10.1128/JB.01159-06

Berg, I. A. (2011). Ecological aspects of the distribution of different autotrophic $\mathrm{CO}_{2}$ fixation pathways. Appl. Environ. Microbiol. 77, 1925-1936. doi: 10.1128/ AEM.02473-10

Berg, I. A., Kockelkorn, D., Ramos-Vera, W. H., Say, R. F., Zarzycki, J., Hügler, M., et al. (2010). Autotrophic carbon fixation in archaea. Nat. Rev. Microbiol. 8, 447-460. doi: 10.1038/nrmicro2365
Given that RubisCO form I and form II have different capabilities to discriminate between $\mathrm{CO}_{2}$ and $\mathrm{O}_{2}$ (Berg, 2011) and both $\mathrm{CO}_{2}$ and $\mathrm{O}_{2}$ concentrations can be highly variable in hydrothermal vent habitats (Perner et al., 2013 and references therein), the ability to rapidly react to environmental $\mathrm{CO}_{2}$ and $\mathrm{O}_{2}$ changes may pose a benefit for local organisms with both forms of RubisCO. A quick response to increasing $\mathrm{O}_{2}$ levels may be the key to successfully colonizing dynamic hydrothermal environments. Having understood some of the possible interactions between the proteins encoded by our metagenomic fragment, this knowledge could now be transferred to a closely related cultured representative. Distinct experiments under different environmental conditions such as high/low $\mathrm{CO}_{2}$ or $\mathrm{O}_{2}$ concentrations could be performed and changes in the transcriptome investigated.

\section{AUTHOR CONTRIBUTIONS}

SB planned and performed experiments, performed computational analyses, and wrote the paper. MP designed the research project, planned experiments, and wrote the paper.

\section{FUNDING}

SB was supported by grants from the Deutsche Forschungsgemeinschaft (DFG) (PE1549/5 1).

\section{ACKNOWLEDGMENTS}

We thank Birte Claßen and Laura Lindloff for helping us to construct the double mutant transposon libraries and Constantin König for excellent technical support with the CbbM mobility shift assays.

\section{SUPPLEMENTARY MATERIAL}

The Supplementary Material for this article can be found online at: http://journal.frontiersin.org/article/10.3389/fmicb. 2017.01303/full\#supplementary-material

Bertani, G. (1951). Studies on lysogenesis. I. The mode of phage liberation by lysogenic Escherichia coli. J. Bacteriol. 62, 293-300.

Böhnke, S., and Perner, M. (2015). A function-based screen for seeking RubisCO active clones from metagenomes: novel enzymes influencing RubisCO activity. ISME J. 9, 735-745. doi: 10.1038/ismej. 2014.163

Bon, M., and Orland, H. (2011). TT2NE: a novel algorithm to predict RNA secondary structures with pseudoknots. Nucleic Acids Res. 39:e93. doi: 10.1093/ nar/gkr240

Bradford, M. M., and Williams, W. L. (1976). New, rapid, sensitive method for protein determination. Fed. Proc. 35, 274-274.

Charoenpanich, P., Meyer, S., Becker, A., and McIntosh, M. (2013). Temporal expression program of quorum sensing-based transcription regulation in Sinorhizobium meliloti. J. Bacteriol. 195, 3224-3236. doi: 10.1128/JB. 00234-13 
Dangel, A. W., Luther, A., and Tabita, F. R. (2014). Amino acid residues of RegA important for interactions with the CbbR-DNA complex of Rhodobacter sphaeroides. J. Bacteriol. 196, 3179-3190. doi: 10.1128/JB.01842-14

Dangel, A. W., and Tabita, F. R. (2015). CbbR, the master regulator for microbial carbon dioxide fixation. J. Bacteriol. 197, 3488-3498. doi: 10.1128/JB.00442-15

Dubbs, J. M., and Tabita, F. R. (2003). Interactions of the cbbII promoter-operator region with CbbR and RegA (PrrA) regulators indicate distinct mechanisms to control expression of the two cbb operons of Rhodobacter sphaeroides. J. Biol. Chem. 278, 16443-16450. doi: 10.1074/jbc.M211267200

Dubbs, J. M., and Tabita, F. R. (2004). Regulators of nonsulfur purple phototrophic bacteria and the interactive control of $\mathrm{CO}_{2}$ assimilation, nitrogen fixation, hydrogen metabolism and energy generation. FEMS Microbiol. Rev. 28, 353-376. doi: 10.1016/j.femsre.2004.01.002

Dubbs, P., Dubbs, J. M., and Tabita, F. R. (2004). Effector-mediated interaction of CbbRI and CbbRII regulators with target sequences in Rhodobacter capsulatus. J. Bacteriol. 186, 8026-8035. doi: 10.1128/JB.186.23.8026-8035.2004

Ellis, R. J. (1979). Most abundant protein in the world. Trends Biochem. Sci. 4, 241-244. doi: 10.1016/0968-0004(79)90212-3

Field, C. B., Behrenfeld, M. J., Randerson, J. T., and Falkowski, P. (1998). Primary production of the biosphere: integrating terrestrial and oceanic components. Science 281, 237-240. doi: 10.1126/science.281.5374.237

Frost, L. S., Ippen-Ihler, K., and Skurray, R. A. (1994). Analysis of the sequence and gene products of the transfer region of the F sex factor. Microbiol. Rev. 58, $162-210$.

Hauser, T., Popilka, L., Hartl, F. U., and Hayer-Hartl, M. (2015). Role of auxiliary proteins in Rubisco biogenesis and function. Nat. Plants 1:15065. doi: 10.1038/ nplants. 2015.65

Joshi, G. S., Zianni, M., Bobst, C. E., and Tabita, F. R. (2013). Regulatory twist and synergistic role of metabolic coinducer- and response regulator-mediated CbbR-cbbI interactions in Rhodopseudomonas palustris CGA010. J. Bacteriol. 195, 1381-1388. doi: 10.1128/JB.02060- 12

Knapp, G. S., and Hu, J. C. (2010). Specificity of the E. coli LysR-type transcriptional regulators. PLoS ONE 5:e15189. doi: 10.1371/journal.pone.0015189

Kusano, T., and Sugawara, K. (1993). Specific binding of Thiobacillus ferrooxidans $\mathrm{RbcR}$ to the intergenic sequence between the $r b c$ operon and the $r b c R$ gene. J. Bacteriol. 175, 1019-1025. doi: 10.1128/jb.175.4.1019-1025.1993

Maddocks, S. E., and Oyston, P. C. F. (2008). Structure and function of the LysR-type transcriptional regulator (LTTR) family proteins. Microbiology 154, 3609-3623. doi: 10.1099/mic.0.2008/022772-0

Mueller-Cajar, O., Stotz, M., Wendler, P., Hartl, F. U., Bracher, A., and HayerHartl, M. (2011). Structure and function of the AAA+ protein CbbX, a red-type Rubisco activase. Nature 479, 194-199. doi: 10.1038/nature10568

Paoli, G. C., Vichivanives, P., and Tabita, F. R. (1998). Physiological control and regulation of the Rhodobacter capsulatus cbb operons. J. Bacteriol. 180, 4258-4269.

Parry, M. A., Keys, A. J., Madgwick, P. J., Carmo-Silva, A. E., and Andralojc, P. J. (2008). Rubisco regulation: a role for inhibitors. J. Exp. Bot. 59, 1569-1580. doi: 10.1093/jxb/ern084

Perner, M., Gonnella, G., Hourdez, S., Böhnke, S., Kurtz, S., and Girguis, P. (2013). In situ chemistry and microbial community compositions in five deepsea hydrothermal fluid samples from Irina II in the Logatchev field. Environ. Microbiol. 15, 1551-1560. doi: 10.1111/1462-2920.12038

Perner, M., Ilmberger, N., Köhler, H. U., Chow, J., and Streit, W. R. (2011). "Emerging fields in functional metagenomics and its industrial relevance: overcoming limitations and redirecting the search for novel biocatalysts," in Handbook of Moleculare Microbial Ecology II: Metagenomics in Different Habitats, ed. F. J. de Bruijn (Hoboken, NJ: Blackwell), 484-485.

Qiagen (2003). TheQiaexpressionistTM, A Handbook for High-Level Expression and Purifiction of 6xHis-Tagged Protein, 5th Edn. Hilden: Qiagen.
Raven, J. A. (2009). Contributions of anoxygenic and oxygenic phototrophy and chemolithotrophy to carbon and oxygen fluxes in aquatic environments. Aquat. Microb. Ecol. 56, 177-192. doi: 10.3354/ame01315

Raven, J. A. (2013). Rubisco: still the most abundant protein of Earth? New Phytol. 198, 1-3. doi: 10.1111/nph.12197

Rice, P., Longden, I., and Bleasby, A. (2000). EMBOSS: the European molecular biology open software suite. Trends Genet. 16, 276-277. doi: 10.1016/S01689525(00)02024-2

Rosano, G. L., and Ceccarelli, E. A. (2014). Recombinant protein expression in Escherichia coli: advances and challenges. Front. Microbiol. 5:172. doi: 10.3389/ fmicb.2014.00172

Schell, M. A. (1993). Molecular biology of the LysR family of transcriptional regulators. Annu. Rev. Microbiol. 47, 597-626. doi: 10.1146/annurev.mi.47. 100193.003121

Solovyev, V., and Salamov, A. (2011). "Automatic annotation of microbial genomes and metagenomic sequences," in Metagenomics and Its Applications in Agriculture, Biomedicine and Environmental Studies, ed. R. W. Li (Hauppauge, NY: Nova Science Publishers), 61-78.

Tabita, F. R., Hanson, T. E., Li, H., Satagopan, S., Singh, J., and Chan, S. (2007). Function, structure, and evolution of the RubisCO-like proteins and their RubisCO homologs. Microbiol. Mol. Biol. Rev. 71, 576-599. doi: 10.1128/ MMBR.00015-07

Treangen, T. J., Abraham, A. L., Touchon, M., and Rocha, E. P. (2009). Genesis, effects and fates of repeats in prokaryotic genomes. FEMS Microbiol. Rev. 33, 539-571. doi: 10.1111/j.1574-6976.2009.00169.x

Tsai, Y. C., Lapina, M. C., Bhushan, S., and Mueller-Cajar, O. (2015). Identification and characterization of multiple rubisco activases in chemoautotrophic bacteria. Nat. Commun. 6:8883. doi: 10.1038/ncomms9883

van Keulen, G., Ridder, A. N., Dijkhuizen, L., and Meijer, W. G. (2003). Analysis of DNA binding and transcriptional activation by the LysR-type transcriptional regulator CbbR of Xanthobacter flavus. J. Bacteriol. 185, 1245-1252. doi: 10.1128/JB.185.4.1245-1252.2003

Varaljay, V. A., Satagopan, S., North, J. A., Witte, B., Dourado, M. N., Anantharaman, K., et al. (2016). Functional metagenomic selection of ribulose 1, 5-bisphosphate carboxylase/oxygenase from uncultivated bacteria. Environ. Microbiol. 18, 1187-1199. doi: 10.1111/1462-2920.13138

Wei, X., Sayavedra-Soto, L. A., and Arp, D. J. (2004). The transcription of the cbb operon in Nitrosomonas europaea. Microbiology 150, 1869-1879. doi: 10.1099/ mic.0.26785-0

Witte, B., John, D., Wawrik, B., Paul, J. H., Dayan, D., and Tabita, F. R. (2010). Functional prokaryotic RubisCO from an oceanic metagenomic library. Appl. Environ. Microbiol. 76, 2997-3003. doi: 10.1128/AEM. 02661-09

Yosef, I., Irihimovitch, V., Knopf, J. A., Cohen, I., Orr-Dahan, I., Nahum, E., et al. (2004). RNA binding activity of the ribulose-1,5bisphosphate carboxylase/oxygenase large subunit from Chlamydomonas reinhardtii. J. Biol. Chem. 279, 10148-10156. doi: 10.1074/jbc.M30860 2200

Conflict of Interest Statement: The authors declare that the research was conducted in the absence of any commercial or financial relationships that could be construed as a potential conflict of interest.

Copyright (c) 2017 Böhnke and Perner. This is an open-access article distributed under the terms of the Creative Commons Attribution License (CC BY). The use, distribution or reproduction in other forums is permitted, provided the original author(s) or licensor are credited and that the original publication in this journal is cited, in accordance with accepted academic practice. No use, distribution or reproduction is permitted which does not comply with these terms. 